\title{
The moral complexity of climate change and the need for a multidisciplinary perspective on climate ethics
}

\author{
Marco Grasso • Ezra M. Markowitz
}

Received: 25 November 2014 / Accepted: 29 December 2014 / Published online: 3 February 2015

(C) Springer Science+Business Media Dordrecht 2015

Al Gore, who was awarded the 2007 Nobel Peace Prize jointly with the Intergovernmental Panel on Climate Change (IPCC) for their efforts to identify and combat climate change, claims that climate change "is not a political issue... [it] is a moral issue, one that affects the survival of human civilization" (Gore 2007). Similarly, James Hansen, who until recently was NASA's leading climatologist, has argued that "the predominant moral issue of the 21st century, almost surely, will be climate change, comparable to Nazism faced by Churchill in the 20th century and slavery faced by Lincoln in the 19th century" (Hansen 2010). In recent years, these and dozens of other scientists, philosophers, politicians, religious and spiritual leaders, artists, businesspersons and others have spoken forcefully — and from a wide diversity of perspectives - about the ethical and moral dimensions of climate change. As Steve Gardiner (2004: 556), a leading scholar in the emerging multidisciplinary field of climate ethics, has put it, climate change is "fundamentally an ethical issue," one that challenges our established morality and threatens our lives and our world (Gardiner 2004; Jamieson 2008).

Motivated in part by the diverse and complex ethical considerations that have been raised by philosophical scholarship regarding climate change, scholars have begun to examine the "ethics of climate change" from a wide variety of disciplinary and multidisciplinary perspectives. In addition to moral and political philosophers, practical ethicists, and political theorists, a growing number of economists, political scientists, geographers, psychologists, legal scholars and others have shown a keen interest in examining and explicating the ethical dimensions of climate change from both normative and positive (descriptive) perspectives.

Given the rapid growth of multidisciplinary scholarship on the ethical issues raised by global climate change, this Special Issue of Climatic Change aims at highlighting cutting-edge research that explores climate ethics from a wide variety of disciplinary and multidisciplinary perspectives, including work by philosophers, economists, political scientists, geographers,

This article is part of a special issue on "Multidisciplinary perspectives on climate ethics" with guest editors Marco Grasso and Ezra M. Markowitz.

M. Grasso ( $\square)$

Department of Geography, Environment and Development Studies Birkbeck, University of London,

32 Tavistock Square, London WC1H 9EZ, UK

e-mail:m.grasso@bbk.ac.uk

E. M. Markowitz

Department of Environmental Conservation, University of Massachusetts Amherst, Amherst, MA, USA 
psychologists, and legal scholars. Our hope is that this Special Issue generates both novel insights into the drivers and inhibitors of meaningful action on climate change as well as exciting new directions for future research.

\section{Background and related extant work}

Both the Special Issue's theoretical grounding and its focus on multidisciplinary perspectives stem from an acknowledgment of the "unavoidability of justice" in the highly unjust context of global climate change, as claimed by Shue (1992: 373) in his seminal work. Such unavoidability, according to Shue, is due to three reasons. First, climate negotiations are characterized by structural injustice. Second, it is the rich countries that historically have caused most of the "dangerous anthropogenic interference with the climate system", yet it is the poorer countries (and citizens) who will face the greatest negative impacts from climate change. And third, avoiding justice would penalize the vital interests of poor countries in favour of the trivial ones of rich countries. As Shue, Jamieson, Gardiner, Caney - "the climate ethics 'gangs of four"' (Jamieson 2013: xii) — and other scholars have made clear over the past 30 years, climate change involves a multitude of ethically significant features, issues, challenges and considerations, whether our interest is in its causes, its consequences or the potential human responses to the issue. For example, ethical arguments arise whenever we attempt to address the question of who should pay for climate mitigation or adaptation efforts, as well as when we attempt to identify the "winners" and "losers" of future changes to the earth's climate and other linked systems. Similarly, any discussions about potential institutional arrangements for dealing with climate change and its consequences involve complex ethical considerations and principles.

To date, work on climate ethics has been dominated by normative assessments of the issue and its features, primarily carried out by moral and political philosophers. This body of research has produced a number of ground-breaking and foundational works, upon which nearly all of the scholarship included in the Special Issue builds. Many of the most prominent of these foundational texts are included in the landmark collection edited by Gardiner et al. in 2010. Besides articles included in that volume (and more generally besides the works of its four editors), other significant philosophical contributions in this area include: Singer's One Atmosphere (2002); Miller's Global Justice and Climate Change: How Should Responsibilities Be Distributed? (2008); and Vanderheiden's Atmospheric Justice. A Political Theory of Climate Change (2008a).

Recently, a growing number of scholars from different perspectives and scholarly fields have begun to build upon moral and political philosophical work on climate change, expanding the study and application of climate ethics in numerous directions. Among these recent efforts, some of the most significant contributions include: the edited volume by Adger et al., Fairness in Adaptation to Climate Change (2006); Baer's and colleagues Greenhouse Development Rights: Towards an Equitable Framework for Global Climate Policy (2008); Vanderheiden's Political Theory and Global Climate Change (2008b); O'Brien, Lera St. Clair and Kristoffersen's Climate Change, Ethics and Human Security (2010); Arnold's The Ethics of Global Climate Change (2011); and Harris's Ethics And Global Environmental Policy. Cosmopolitan Conceptions of Climate Change (2011). Significant examples of the application of climate ethics to international climate politics can be found, for instance, in Grasso and Roberts (2014); and, with specific reference to adaptation funding, in Ciplet et al. (2013). Or, for the application to climate science, for instance, in Steinberger et al. (2012); to economics, for instance, in Tavoni et al. (2012); to psychology, for instance, in Markowitz and Shariff (2012).

Philosophical contributions to climate ethics have primarily been published in journals dealing with applied ethics and environmental philosophy, with fewer articles appearing in 
major interdisciplinary journals on climate and environmental change. Political, economic and other less strictly philosophical contributions to climate ethics have tended to be dispersed more widely, including in journals oriented towards international climate/environmental policy, environmental economics journals, environmental law journals, and in geography, political sciences, political economy and international relations journals. In brief, the different perspectives and approaches to climate ethics have been scattered across disparate, largely disciplinary, literatures and publications. This has significantly hampered the kind of cross-disciplinary communication and scholarship on climate change that Climatic Change aims to promote and that the complexity and multifaceted nature of the issue demands.

On the contrary, the contributions to this Special Issue bring together a diverse range of perspectives on climate ethics. The primary distinguishing feature of this collection is, in fact, "multidisciplinarity." In order to better articulate the impact that such an inclusive perspective could make to the broad field of climate ethics (and beyond), we need first to briefly describe the theoretical building blocks that shape the logic and structure of both the climate ethics workshop we convened in September 2013 ("Multidisciplinary perspectives on climate ethics," September 26 and 27, Como, Italy) and the contributions produced by that workshop that are included here.

Consistent with the dominant philosophical literature referenced above, we identify three major types of ethically relevant domains or challenges in the context of global climate change: (i) coordination of emissions reductions efforts; (ii) coordination of adaptation efforts; and, (iii) planning for compensation in the face of future losses. Furthermore, we agree with claims made by a wide variety of theorists that ethical issues arising from each of these challenges hold significant implications both for individuals and for groups (i.e., communities, states, and other national and international organizations and institutions). That is to say, each of these entities are "subjects of justice" —entities to whom pertain obligations, duties and rights in the context of climate change, if to differing extents and in different ways - and thus need to be considered within the domain of climate ethics. In this regard, we do not endorse Sinnott-Armstrong's (2005) denial of personal moral obligation because of the impossibility of defending any moral arguments given the scale of the problems involved by global climate change. Neither do we espouse Johnson's (2003) view of climate change as solely a collectiveaction problem because of the supposed impossibility for individuals of dealing with the moral implications of the tragedy of global commons. Therefore, consistent with the liberal literature on global justice (e.g. Caney 2005; Hourdequin 2010; Nolt 2011), we hold that both individuals and collectives are subjects of climate justice.

Taken together, the contributions to this Special Issue cover, both according to a disciplinary and a multidisciplinary perspective, the broad field of climate ethics as delimited, for instance, in recent authoritative overviews (Gardiner 2010; Okereke 2010). In particular, the contributions published deal with a number of ethical issues that, to a large extent, were initially raised - but not necessarily addressed - by early work in philosophy and climate change, including:

- the criticality of mitigation and burden sharing (Morrow, this issue);

- the threats posed by climate impacts to human life (Nolt, this issue);

- the controversial nature of geoengineering (Preston, this issue; Corner and Pidgeon, this issue);

- the setting of abatement targets (Llavador et al., this issue);

- the scales of the ethical issues characterizing adaptation (Graham et al., this issue);

- the capacity of current governance systems to handle questions of justice (Milkoreit, this issue);

- the role of moral communication (Rees et al., this issue; Tauber et al., this issue);

- and, the viability of justice in international regimes (Mayer, this issue). 
Moreover, these contributions fulfil the ultimate objective of applying the foundational philosophical work on climate ethics, emphasized above, to concrete moral issues raised by the complexity of climate change "on the ground." For example, in a finer grained perspective, the included articles highlight questions related to institutional design processes, selection of mitigation and/or adaptation initiatives, technological dilemmas, international legal frameworks, local justice considerations, and perception and communication of the associated risks, among others. Thus, the collection is consistent with and builds upon the state-of-the-art in the rapidly growing field of climate ethics, which has itself built off of the strong foundation provided by early and recent moral philosophical approaches to climate ethics and now tends to directly applying analyses of ethical considerations to real-world work on climate change.

On the basis of this theoretical background and of the related considerations, the Special Issue is structured so as to highlight many of the most significant wide-ranging ethical issues entailed by climate change. These include normative assessments and prescriptions (e.g., economic analyses of "just" distributions of costs and benefits) as well as more positive accounts (e.g., identification of features of the problem that subjectively influence whether or not normative ethical considerations are taken into account by decision-makers). Thus, the contributions selected for inclusion in the Special Issue deal both with the various dimensions of climate ethics briefly discussed above as well as with the different nature of (collective and individual) subjects of justice included, covering many of the diverse moral issues that climate ethics entails. Only by doing so do we believe that it is possible to forge a broader understanding of the multifaceted problems that moral decision-making in the context of climate change raises, and that the Special Issue aims to contribute to disentangle. Moreover, by highlighting and revealing the multidisciplinary nature of climate change as an ethical issue (including the many ways in which ethical principles are realized in the real world of climate change politics), the Special Issue builds upon and expands the existing compilations of work in this domain. In this way, contributions to the Special Issue help reveal the multitude of ways in which foundational, moral and political philosophical work on climate ethics can be and is already being applied in the real world.

\section{Overview of contributions to the Special Issue}

Given these considerations and aims — as well as the diverse readership of Climatic Changewe have purposively oriented the Special Issue towards contributions that have the potential for stimulating cross-cutting future research on new and relatively unexplored themes and topics in the domain of climate ethics and beyond.

In the set of included papers that take a predominantly philosophical approach (Morrow; Nolt; Preston), these themes include a novel perspective on the moral nature of mitigation policy, new ethics-based risk-assessment methods, and some of the most prominent moral issues raised by anthropogenic forcing on the climate system, including geoengineering.

David Morrow, in "Wants and needs in mitigation policy", argues that, by and large, moral disagreements about mitigation policies arise from implicit disagreements about the misspecification of the moral significance of the distinction between wants and needs. In particular, he claims that rejecting the distinction between wants and needs tends to justify less aggressive mitigation policies, whereas endorsing such a distinction seems to vindicate more aggressive mitigation policies. Morrow concludes by pointing out that both views are intellectually defensible: understanding them can shed light on disagreements over mitigation policy. 
In "Casualties as a moral measure of climate change", John Nolt maintains that casualties caused by climate change have a strong moral significance and are a universal measure of the harms brought about by the issue. Therefore, he suggests, the harms of climate change should regularly be expressed in terms of casualties since they add substantially to humanity's grasp of the moral costs of the climate crisis. And in "Framing an ethics of climate management for the Anthropocene", Christopher Preston focuses the ethical framing of climate change on the complexities involved in the anthropogenic engineering of the climate system through both negative and positive climate forcers, including non- $\mathrm{CO}_{2}$ factors. His arguments highlight the continued importance of focusing on greenhouse gas and black carbon reductions, yet also raise important considerations regarding unintentional secondary consequences of various climate-related choices. Preston also points out that his novel framing reveals a significant ethical difference between geoengineering accomplished via solar radiation management (SRM) versus through carbon dioxide removal (CDR).

Shifting focus somewhat (but staying in the normative realm), Benoit Mayer, in "Conceiving the rationale for international climate law," proposes a reflection on the elusive rationale for international climate law, on which, in fact, there is currently no consensus. His fundamental claim is that references to "equity" and "common but differentiated responsibilities and respective capabilities" in existing climate law offer insufficient guidance to on-going negotiations, reflecting an agreement to disagree rather than a common vision. In light of this situation, Mayer maintains that the rationale for climate law should be construed as a hybrid narrative reconciling moral aspirations with pragmatic constraints, as a means for seeking a complex interdependence able to emphasize existing national interests in fostering global sustainable development.

Moving to the consideration of economic aspects of climate change, the Special Issue highlights the fundamental and unavoidable role of ethical considerations for favouring cooperation between the North and the South in international emissions reductions. Humberto Llavador and colleagues in "North-South convergence and the allocation of $\mathrm{CO}_{2}$ emissions" show that growth expectations in the North and the South likely need to be justly scaled back substantially. Feasible growth paths with low levels of emissions would require heavy investments in education and knowledge. According to the authors' thought experiment, Northern and Southern growth should be restricted to about $1 \%$ and $2.5 \%$ per year, respectively, over the next 75 years, in order to achieve climate stabilization goals in their hypothesized two-country world.

Based on a multidisciplinary approach that integrates perspectives from political science, international relations and moral psychology, Manjana Milkoreit, in "Hot deontology and cold consequentialism: an empirical exploration of ethical reasoning among climate change negotiators," identifies both deontological and consequentialist cognitive patterns in ethical thinking among climate change negotiators. Examining the constitutive elements of such ethical thinking through the use of interviews with negotiators and others, Milkoreit finds that many interviewed subjects experience climate change as an "up, close and personal" threat, over which other agents have significant control (rather than as a "cold, cognitive" risk).

In a similar vein, combining methods and perspectives from geography and sociology, Graham and colleagues, in "Towards fair local outcomes in adaptation to sea-level rise," focus on the capacity of local communities to promote just adaptation responses and protection of human rights threatened by climate change. In particular, they present the results of a study that sought to understand the multiple dimensions of fairness of adaptation strategies that exist or can be developed to deal with sea-level rise along the south-east coast of Australia. They argue that understanding nuances in the social values of communities reveals how policies can be adapted to provide fairer outcomes for all community members through processes that create 
the time and space required to establish long-term working relationships between communities and government.

Finally, the Special Issue includes a group of papers which highlight a number of core psychological considerations that arise in the context of climate ethics, particularly with respect to communication. In "Like artificial trees? The effect of framing by natural analogy on public perceptions of geoengineering", Adam Corner and Nick Pidgeon provide an empirical test of one of the most prevalent frames of geoengineering: describing its technologies by analogy to natural processes. Their findings suggest that communicators should be cautious when using natural analogies to communicate about geoengineering with the general public, as frame choice is likely to influence public attitudes and potentially convey undue positivity. In "Guilty conscience: Motivating pro-environmental behavior by inducing negative moral emotions", Jonas Rees and colleagues report results from a study in which they examined the mediating effects of self-focused moral emotions - guilt and shame-on individuals' willingness to take action against climate change. Comparing reactions to information about human-caused versus naturally-occurring environmental disasters, the authors find that individuals' organic emotional reactions to learning about human-caused disasters increase motivation to take action. And in a closely related vein, Susanne Tauber and colleagues, in "Should the moral core of climate issues be emphasized or downplayed in public discourse? Three ways to successfully manage the double-edged sword of moral communication," suggest caution in communicators' use of overtly moralizing language to engage citizens on climate change. Specifically, the authors identify a serious problem for communicators regarding the framing of climate issues in public discourse, namely that moralizing the issue can motivate individuals while at the same time generating defensive reactions that prevent greater issue engagement. In order to obviate the problem they suggest framing persuasive messages in non-moral terms, promoting value-driven group identities and creating messages and campaigns that help develop moral convictions while increasing a sense of agency.

\section{Concluding remarks}

That climate change is an "ethical issue" is nothing new. Philosophers, as well as politicians, climate activists, religious leaders and many others have long highlighted and explored the numerous ethical considerations and challenges that are inseparable from discussions of the causes, consequences and potential human responses to global, anthropogenic climate change. More recently, scholars from a wide variety of perspectives - including, economics, political science, geography, psychology, and law-have begun to examine and build upon these claims, highlighting their implications, both normative and positive, for moral decisionmaking at both the individual and collective levels. This Special Issue brings together a diverse set of authors who are thinking about and applying climate ethics in many different contexts and through many different perspectives. This multidisciplinary approach and extensions to the topic of climate ethics is producing novel insights into both the very nature of the problem that we face as well as the complex and challenging decisions that lie ahead with respect to confronting climate change. We believe that the need for a multidisciplinary approach to climate ethics originates from its capacity to stimulate new collaborations between disparate groups of scholars and practitioners. This process may, in fact, help point the way towards previously unidentified or underappreciated tools, strategies and pathways for successfully dealing with climate change in the future. 
Acknowledgments The authors gratefully acknowledge support from the Center for Interdisciplinary Studies in Economics, Psychology and Social Sciences (CISEPS), Università Milano-Bicocca and from the Chamber of Commerce of Como, Italy. Their financial contribution made it possible to organize the workshop 'Multidisciplinary perspectives on climate ethics' (September 26-27 2013, Lake Como, Italy) where the articles included in this Special Issues were first presented.

\section{References}

Adger WN, Paavola J, Huq S, Mace MJ (2006) Fairness in adaptation to climate change. MIT Press, Cambridge

Arnold DG (2011) The ethics of global climate change. Cambridge Univ Press, Cambridge

Baer P, Fieldaman G, Athanasiou T, Kartha S (2008) Greenhouse Development Rights: towards an equitable framework for global climate policy. Camb Rev Int Aff 21(4):649-669. doi:10.1080/ 09557570802453050

Caney S (2005) Cosmopolitan justice, responsibility and global climate change. LJIL 18, 4:747-775. doi:10. $1017 / \mathrm{S} 0922156505002992$

Ciplet D, Roberts JT, Khan M (2013) The politics of international climate adaptation funding: justice and divisions in the greenhouse. Global Environ Polit 12(2):49-68. doi:10.1162/GLEP a 00153

Gardiner SM (2004) Ethics and global climate change. Ethics 114:555-600. doi:10.1086/382247

Gardiner SM (2010) Ethics and climate change: an introduction. WIREs Clim Chang 1(1):54-66. doi:10.1002/ wec. 16

Gardiner SM, Caney S, Jamieson D, Shue H (2010) Climate ethics. Essential readings. Oxford Univ Press, New York

Gore A (2007) Moving beyond Kyoto. The New York Times, 1 July 2007, p. 413 (New York edition). http:// www.nytimes.com/2007/07/01/opinion/01gore.html. Accessed 22 Nov 2014

Grasso M, Roberts JT (2014) A compromise to break the climate impasse. Nat Clim Chang 4:543-549. doi:10. 1038/nclimate2259

Hansen J (2010) Obama's second chance on the predominant moral issue of this century. The Huffington Post, 5 April 2010. http://www.huffingtonpost.com/dr-james-hansen/obamas-second-chance-on-c_b_525567.html. Accessed 22 Nov 2014

Harris PG (2011) Ethics and global environmental policy. Cosmopolitan conceptions of climate change. Edward Edgar, Cheltenham

Hourdequin M (2010) Climate, collective action and individual ethical obligations. Environ Values 19(4):443464. doi:10.3197/096327110X531552

Jamieson D (2008) The post-Kyoto climate: a gloomy forecast. Geo Int'l Envtl L:537-551

Jamieson D (2013) Reason in a dark time. Why the struggle against climate change failed - and what it means for our future. Oxford Univ Press, New York

Johnson BL (2003) Ethical obligations in a tragedy of the commons. Environ Values 12(3):271-287. doi:10. 3197/096327103129341324

Markowitz EM, Shariff A (2012) Climate change and moral judgment. Nat Clim Chang 2:243-247. doi:10.1038/ nclimate 1378

Miller D (2008) Global justice and climate change: how should responsibilities be distributed? The Tanner Lectures on Human Values, delivered at Tsinghua University, Beijing, March 24-25: 11956

Nolt J (2011) How harmful are the average American's greenhouse gas emissions? Ethics Pol Environ 14(1):310. doi: $10.1080 / 21550085.2011 .561584$

O'Brien K, St L, Clair A, Kristoffersen B (2010) Climate change, ethics and human security. Cambridge Univ Press, Cambridge

Okereke C (2010) Climate justice and the international regime. WIREs Clim Chang 1(3):462-474. doi:10.1002/ wcc. 52

Shue H (1992) The unavoidability of justice. In: Hurrell A, Kingsbury B (eds) International Politics of the Environment. Oxford Univ Press, Oxford, pp 373-397

Singer P (2002) One world: the ethics of globalization, Chapter 2. Yale Univ Press, New Haven, pp 14-50

Sinnott-Armstrong W (2005) It's not my fault: global warming and individual moral obligations. In: SinnottArmstrong W, Howarth RB (eds) Perspectives on climate change: science, economics, politics, ethics. Elsevier, Oxford, pp 258-308 
Steinberger JK, Roberts JT, Peters GP, Baiocchi G (2012) Pathways of human development and carbon emissions embodied in trade. Nat Clim Chang 2:81-85. doi:10.1038/nclimate1371

Tavoni M, Socolow R, Chakravarty S (2012) Safe vs. fair: a formidable trade-off in tackling climate change. Sustainability 4(2):210-226. doi:10.3390/su4020210

Vanderheiden S (2008a) Atmospheric justice. A political theory of climate change. Oxford University Press, New York

Vanderheiden S (2008b) Political theory and global climate change. MIT Press, Cambridge 